\title{
Health Related Lifestyle Behaviors among Undergraduate Medical Students in Patan Academy of Health Sciences in Nepal
}

\author{
Sudarshan Paudel ${ }^{*}$, Krishna Bahadur GC1, Dil Bahadur Bhandari'1, Lilanath Bhandari², \\ Amit Arjyal ${ }^{1}$
}

${ }^{1}$ School of Public Health, Patan Academy of Health Sciences, Lalitpur, Nepal

${ }^{2}$ Hope International College, Purbanchal University, Biratnagar, Nepal

Email: *sudarshanpaudel@gmail.com

How to cite this paper: Paudel, S., GC, K.B., Bhandari, D.B., Bhandari, L. and Arjyal, A. (2017) Health Related Lifestyle Behaviors among Undergraduate Medical Students in Patan Academy of Health Sciences in Nepal. Journal of Biosciences and Medicines, 5, 43-53.

https://doi.org/10.4236/jbm.2017.59005

Received: July 29, 2017

Accepted: September 1, 2017

Published: September 4, 2017

Copyright $\odot 2017$ by authors and Scientific Research Publishing Inc. This work is licensed under the Creative Commons Attribution International License (CC BY 4.0).

http://creativecommons.org/licenses/by/4.0/

\begin{abstract}
Objectives: This descriptive study of 219 undergraduate medical students at Patan Academy of Health Sciences in Nepal was conducted to evaluate the relationships of their demographic variables with a health-promoting lifestyle profile. Methods: The Health Promoting Lifestyle Profile (HPLP) questionnaire was used to study students' lifestyles. We compared the HPLP scores according to gender, residence type, school background and year of study. One-way analysis of variance (ANOVA) and multiple comparison test were conducted to identify significant differences among university year (first, second, third and fourth) groups. Multiple regression analysis was used to analyze the effects of various demographics on the overall HPLP score and the six health-promoting lifestyle subscales. Results: The overall HPLP mean score of participants was $2.60 \pm 0.29$, with the highest mean scores being for spiritual growth $(2.99 \pm 0.42)$ and interpersonal relations $(2.90 \pm 0.35)$, and the lowest mean scores being for health responsibility $(2.39 \pm 0.39)$ and physical activity $(2.25 \pm 0.54)$, respectively. The overall HPLP score of the students was the highest for the first year students at $2.65 \pm 0.26$. The male students had a better overall HPLP score, although female students obtained better score in some sub-scales such as health responsibility, interpersonal relations and nutrition. The students from a public school background had significantly higher scores for health responsibility, physical activity and stress management than those who graduated school level education from a private school. Conclusions: The results of this study reveal that the status of health promoting behaviors among the students was acceptable with ample room for improvement. Implementation of health education and promotion programs with an
\end{abstract}


emphasis on the different dimensions of health lifestyle behaviors is recommended.

\section{Keywords}

Health-Promoting Lifestyle Profile, Medical Student, Nepal

\section{Introduction}

Health lifestyle behavior is considered as the science and art which helps people to change their lifestyle in order to gain optimal health [1]. Lifestyle is a planned effort made by a person. It gives a person the ability to correct and control his/her own health, so as to enjoy one's full health potential and continue to have a healthy lifestyle [2]. It is greatly influenced by culture, family, reference groups, and social class. Lifestyle comprises of the decisions on diet selection, exercise, health responsibility, stress management and the actions that one takes to achieve those decisions [3]. One's health is affected by one's lifestyle, and health promoting behaviors and healthy lifestyles are an important feature to facilitate and maintain one's health [4] [5].

Health promoting behavior is an important factor in the avoidance of many illnesses, and health promotion and disease prevention are directly associated with this behavior [6]. One of the most important associations of chronic diseases such as cancer, high blood pressure, diabetes and heart diseases is healthy lifestyle and hence building healthy lifestyle is one of the best ways to restore or maintain health [7]. Research has established genetic links for disease and discovered relationships between behaviors and disease whereas environmental influences also contribute to the onset and progression of diseases [8].

People are responsible for their own personal health promotion and disease prevention. Therefore, studies that concentrate on young people are important because they are considered as change agent for healthy lifestyle. Students form a large proportion of young adults. Students progressively take the responsibility for their health in line with their physical, psychological, social and sexual developments [9] [10] [11] [12] [13]. The transitional period during the university years is the best time to establish healthy behaviors and it is also the period when habits formed will be carried out for the rest of life [10]. Because of their influence on society as they progress to become responsible adults, students function as a channel to spread matters of self-health promotion. Therefore, the lifestyle they choose also affects the lifestyle of others [14] [15] [16].

Medical students encounter multiple socio-psychological adaptations as they change from self-indulgent young people to responsible physicians. Doctors, in turn, are role models of society, and their lifestyle and health conditions are highly valued by the general public in the country. As they are such a valuable part of society, it is important to know the Health Promoting Lifestyle Profile of 
Medical Students. A detailed survey of health promoting lifestyles has not been done in Nepali college students or medical students. The demographic factors that affect the HPLP are also not known. Knowledge of those factors could help to design effective interventions to improve the HPLP of medical students.

This study aimed to examine the health-promoting lifestyles of undergraduate medical students to determine the relationships between demographic parameters and their year level with their overall score on the Health Promoting Lifestyle Profile (HPLP) consisting of the six parameters which encompassed health responsibility, spiritual growth, physical activity, interpersonal relations, nutrition, and stress management.

\section{Methods}

This study utilized the Health-Promoting Lifestyle Profile (HPLP) survey developed by Walker et al. [17]. The HPLP has been used by many researchers for assessing health promoting lifestyle and is reported to have high validity and reliability for use in different populations. The English version of this overall scale, which was administered for data collection in this research, reported a Cronbach alpha of 0.877 . The questionnaire that was used had two sections, namely, demographic variables and health promotion lifestyle profile questionnaires.

The HPLP survey consists of 52 questions. These questions are divided into six subscales, namely, spiritual growth-9 questions, interpersonal relations-9 questions, nutrition-9 questions, physical activity-8 questions, health responsibility-9 questions and stress management- 8 questions. Each question is answered based on a 4-point Likert scale with a scoring range of 1 to 4 for never, sometimes, often, and routinely, respectively. The lowest possible individual overall score of the HPLP is $52(1 \times 52)$ and the highest possible is $208(4 \times 52)$. For each subscale, the scores for the questions were added and divided by the number of items in the subscale for obtaining the subscale scores. The overall score is obtained by adding the scores for all the items and dividing by the total number of items. The lowest possible overall or mean score is 1 and the highest possible overall or mean score is 4 . The higher the mean score obtained, higher is the index of a health-promoting lifestyle.

In this study the questionnaire-based HPLP survey was done on MBBS students, aged between 17 and 32 (average age 21) years and studying in the first to fourth year of their medical course (Bachelor of Medicine and Bachelor of Surgery, MBBS) at Patan Academy of Health Sciences, Nepal. The research questionnaires $(\mathrm{N}=240)$ were distributed to the students. To ensure anonymity, the questionnaire was self-administered, no name was required on the questionnaire and it was returned to a designated box.

The analysis was performed using Statistical Package for the Social Sciences (SPSS) v16.0. Distribution of socio-demographic characteristics, and characteristics of lifestyle of the students who participated in the study were evaluated and difference between mean score in the HPLP overall and in the subscales was analyzed. The statistical differences between the groups are in terms of so- 
cio-demographics and HPLP. The HPLP scores were compared according to gender, residence type, school background and year of study. Scores were analyzed using independent $t$-test and analysis of variance (ANOVA) test. Multiple comparison test were conducted to identify significant differences among university year (first, second, third and fourth) groups. The post-hoc test was performed to determine the direction and significance of differences between the groups. A p-value of 0.05 was considered to be statistically significant.

All the students were eligible to participate and participation in the study was voluntary. Consent was taken from them before filling the questionnaire.

\section{Results}

The survey was completed by 219 (121 males, 98 females) students (91\%) amongst 240 students who were handed the questionnaires (Table 1). All four academic years, years one through four, participated. The average age of first-year students

Table 1. Demographic data of the participants.

\begin{tabular}{|c|c|c|}
\hline Variable & Numbers (\%) & Age, years $($ mean $\pm S D)$ \\
\hline Total & $219(100)$ & \\
\hline \multicolumn{3}{|l|}{ Gender } \\
\hline Male & $121(55.3)$ & $21.08 \pm 2.39$ \\
\hline Female & $98(44.7)$ & $19.92 \pm 1.46$ \\
\hline \multicolumn{3}{|l|}{ Proficiency level education } \\
\hline Higher Secondary $(10+2)$ & $209(95.4)$ & $20.45 \pm 1.97$ \\
\hline PCL (Allied Health Sciences) & $10(4.6)$ & $22.90 \pm 3.32$ \\
\hline \multicolumn{3}{|c|}{ Geographical types of residence } \\
\hline Rural & $112(51.1)$ & $20.87 \pm 2.16$ \\
\hline Urban & $107(48.9)$ & $20.24 \pm 1.99$ \\
\hline \multicolumn{3}{|c|}{ School background (studied grade $8,9,10$ ) } \\
\hline Community School & $98(44.7)$ & $21.07 \pm 2.18$ \\
\hline Private School & $121(55.3)$ & $20.15 \pm 1.95$ \\
\hline \multicolumn{3}{|c|}{ Fee payment scheme in medical school } \\
\hline No Scholarship & $115(52.5)$ & $20.05 \pm 1.99$ \\
\hline Partial scholarship & $65(29.7)$ & $21.22 \pm 2.06$ \\
\hline Full Scholarship & $39(17.8)$ & $20.97 \pm 2.13$ \\
\hline \multicolumn{3}{|c|}{ Year of study in medical school } \\
\hline First year & $65(29.7)$ & $19.22 \pm 2.06$ \\
\hline Second year & $45(20.5)$ & $19.87 \pm 1.29$ \\
\hline Third year & $56(25.6)$ & $20.89 \pm 1.81$ \\
\hline Fourth year & $53(24.2)$ & $22.45 \pm 1.41$ \\
\hline
\end{tabular}


was $19.22(2.06 \mathrm{SD})$ while it was 22.45 (1.41 SD) in case of fourth-year students. The mean age of male respondents was $21.08 \pm 1.5$ years (range 17 - 32 years). The mean age of female respondents was $19.92 \pm 1.46$ years (range $17-24$ years).

The mean and standard deviation of the total health promoting behaviors were $2.60 \pm 0.29$ out of a score of four. The result also indicated that the status of the health promoting behaviors among 142 students (64.9\%) were relatively good (mean score range 2.5 - 4) and remaining 77 students were poorer.

The highest level of health promoting behaviors related to spiritual growth with a score of $2.99 \pm 0.42$. This was followed by interpersonal relations with $2.90 \pm 0.35$, stress management with $2.61 \pm 0.44$, nutrition with $2.44 \pm 0.41$, health responsibility with $2.39 \pm 0.39$ and physical activity with $2.25 \pm 0.54$ respectively (Table 2).

The first year students showed higher scores for overall HPLP at $2.65 \pm 0.26$, spiritual growth at $3.12 \pm 0.38$, and stress management at $2.54 \pm 0.41$ but other domains were not higher than that for the students in other years (Table 2). Second year students got the lowest overall score at $2.52 \pm 0.31$. The fourth year students were weakest in interpersonal relations. A significant difference was noted in between the various years in the domains of spiritual growth and stress management.

Table 3 shows segregated data on the basis of sex, residence type and school background. Differences were observed in the total HPLP scores and sub-scale scores between subgroups of participants' characteristics. The males had an overall HPLP mean score of $2.62 \pm 0.29$, while the females had an overall HPLP mean score of $2.58 \pm 0.29$. The rural students had an HPLP score of $2.62 \pm 0.28$, while urban students had a score of $2.59 \pm 0.30$. The result asserted that students having a rural residence background are better in overall HPLP except nutrition. There was a significant association with the type of school and HPLP with the score being higher $(2.69 \pm 0.41)$ in those with a public school background compared to those with a private school background $(2.54 \pm 0.44)$.

Table 2. Mean distribution of Health Promoting Lifestyle Profile II (HPLP-II) scores according to year.

\begin{tabular}{|c|c|c|c|c|c|c|c|}
\hline Year & $\begin{array}{c}\text { Health } \\
\text { Responsibility }\end{array}$ & $\begin{array}{l}\text { Physical } \\
\text { Activity }\end{array}$ & Nutrition & $\begin{array}{l}\text { Spiritual } \\
\text { Growth }\end{array}$ & $\begin{array}{c}\text { Interpersonal } \\
\text { Relations }\end{array}$ & $\begin{array}{c}\text { Stress } \\
\text { Management }\end{array}$ & Overall HPLP \\
\hline All students & $2.39 \pm 0.39$ & $2.25 \pm 0.54$ & $2.44 \pm 0.41$ & $2.99 \pm 0.42$ & $2.90 \pm 0.35$ & $2.61 \pm 0.44$ & $2.60 \pm 0.29$ \\
\hline First year & $2.37 \pm 034$ & $2.24 \pm 0.51$ & $2.44 \pm 0.38$ & $3.12 \pm 0.38$ & $2.91 \pm 0.33$ & $2.78 \pm 0.38$ & $2.65 \pm 0.26$ \\
\hline Second year & $2.34 \pm 0.39$ & $2.19 \pm 0.58$ & $2.36 \pm 0.46$ & $2.85 \pm 0.42$ & $2.89 \pm 0.35$ & $2.45 \pm 0.45$ & $2.52 \pm 0.31$ \\
\hline Third year & $2.38 \pm 0.40$ & $2.26 \pm 0.51$ & $2.41 \pm 0.42$ & $2.97 \pm 0.44$ & $2.93 \pm 0.34$ & $2.63 \pm 0.46$ & $2.60 \pm 0.31$ \\
\hline Fourth year & $2.45 \pm 0.41$ & $2.29 \pm 0.57$ & $2.53 \pm 0.38$ & $2.97 \pm 0.39$ & $2.88 \pm 0.41$ & $2.54 \pm 0.41$ & $2.62 \pm 0.29$ \\
\hline$f_{\text {value }}$ & 0.728 & 0.314 & 1.476 & 3.947 & 0.184 & 5.956 & 1.816 \\
\hline$p$ value & 0.536 & 0.815 & 0.222 & $0.009^{*}$ & 0.908 & $0.001^{\star}$ & 0.145 \\
\hline
\end{tabular}

The values are expressed as means $\pm \mathrm{SD}$, and one-way analysis of variance (ANOVA) and multiple comparison procedures using the LSD test were conducted. 
Table 3. Distribution of Health Promoting Lifestyle Profile (HPLP) scores according to gender, residence type, school background and higher education.

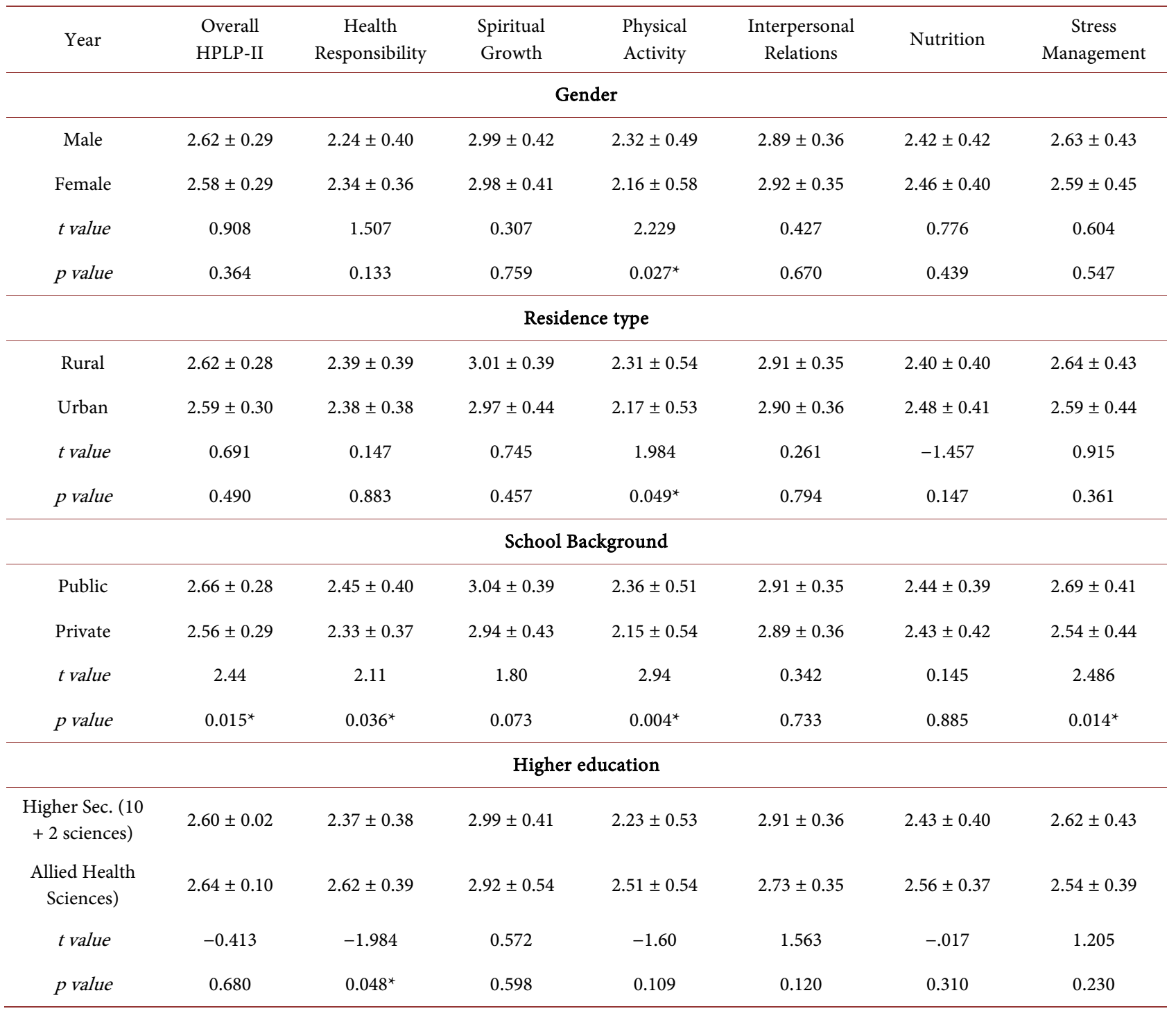

The values are expressed as means $\pm \mathrm{SD}$, and t-tests were conducted. ${ }^{*} P<0.05$.

The two-sample correlation analysis averred that there were significant differences found between groups of gender, residence type and school background in the physical activity subscale. In addition, there was significant difference between respondents having a background of public and private school in the domains of health responsibility $(p=0.036)$, physical activity $(p=0.004)$ and stress management $(p=0.014)$ along with overall HPLP $(p=0.015)$. The health responsibility score was also significantly different between those who underwent higher secondary school compared to those who carried out proficiency certificate level in allied health sciences $(p=0.048)$.

Multiple regression analysis of the six personal variables with the overall HPLP score and six health-promoting lifestyle subscales scores was performed to determine which independent variables were good predictors of a healthy life- 
style in the participants. With all six variables in the regression model, the variance in the participants of health responsibility, spiritual growth, physical activity, interpersonal relation, nutrition, stress management and overall HPLP contributed 5.4\%, 3.0\%, 6.6\%, 1.5\%, 3.6\%, 6.7\% and 3.1\%, respectively (Table 4).

A comparison of the frequency of students with the poor and relatively good HPLP across various demographic categories (Table 5) revealed that students from public school background have relatively good HPLP than that of private school background whereas no significant association was found between demographic variables like gender and residence type with health lifestyle behavior scale scores.

\section{Discussion}

Patan Academy of Health Sciences (PAHS) enrolls students based on the "Social Inclusion Matrix (SIM)" to address social accountability and inclusiveness in the spirit of PAHS Act [18] as well as the Constitution of Nepal. That system has encompassed gender, school background (community/public), educational background (higher secondary; $10+2$ and proficiency certificate level in allied health sciences) and place of permanent residence (rural and urban). Additionally, there are three provisions to get preference for admission which are; "ultra poor", "rural resident" and "grades 8,9 and 10 in community school". PAHS has offered three categories of fee payment schemes namely "no pay", "half pay", "full pay" so as to enable socially and economically disadvantaged applicants to study medicine if they get selected. In addition, 5\% students that have been enrolled are from Allied Health Sciences background which is not in practice in other medical schools in Nepal. The representation of public or community schools with $44.7 \%$ students at PAHS was due to SIM. This enabled our study to assess the role of the various demographic variables like school background, educational background and place of permanent residence with the HPLP scores.

The data showed that the overall HPLP score of respondents is $2.60 \pm 0.29$ which is relatively good. A HPLP of greater than 2.5 is considered to be good.

Table 4. Independent baseline predictors of health-promoting lifestyle profile II (HPLP-II) and demographic data of participants.

\begin{tabular}{|c|c|c|c|c|c|c|c|}
\hline Year & $\begin{array}{l}\text { Overall } \\
\text { HPLP-II }\end{array}$ & $\begin{array}{c}\text { Health } \\
\text { responsibility }\end{array}$ & $\begin{array}{l}\text { Spiritual } \\
\text { growth }\end{array}$ & $\begin{array}{l}\text { Physical } \\
\text { activity }\end{array}$ & $\begin{array}{l}\text { Interpersonal } \\
\text { relations }\end{array}$ & Nutrition & $\begin{array}{c}\text { Stress } \\
\text { management }\end{array}$ \\
\hline Gender (male/female) & -0.018 & -0.048 & -0.003 & -0.109 & 0.011 & 0.050 & -0.021 \\
\hline $\begin{array}{l}\text { Higher Education }(10+ \\
\text { 2/PCL })\end{array}$ & 0.022 & 0.235 & -0.091 & 0.205 & -0.188 & 0.168 & -0.201 \\
\hline $\begin{array}{l}\text { Types of residence } \\
\text { (Rural/Urban) }\end{array}$ & 0.030 & 0.086 & 0.013 & -0.010 & -0.029 & 0.079 & 0.035 \\
\hline $\begin{array}{l}\text { School Background } \\
\text { (Public/private) }\end{array}$ & -0.105 & -0.082 & -0.129 & -0.096 & -0.044 & -0.114 & -0.172 \\
\hline $\begin{array}{c}\text { Tuition fee } \\
\text { (No/Partial/Full) }\end{array}$ & 0.002 & 0.050 & -0.012 & 0.082 & -0.034 & -0.067 & 0.004 \\
\hline MBBS year & -0.009 & 0.016 & -0.041 & 0.009 & 0.000 & 0.026 & -0.067 \\
\hline $\mathrm{R}^{2}$ & 0.031 & 0.054 & 0.030 & 0.066 & 0.015 & 0.036 & 0.067 \\
\hline
\end{tabular}


Table 5. Distribution of health lifestyle behavior scale scores of students.

\begin{tabular}{ccccc}
\hline \multirow{2}{*}{ Demographic variables } & $\begin{array}{c}\text { Relatively Good HPLP } \\
(\mathrm{n}=142)\end{array}$ & $\begin{array}{c}\text { Poor HPLP } \\
(\mathrm{n}=77)\end{array}$ & $p$-value \\
\hline \multirow{2}{*}{ Gender } & Male & $77(63.6 \%)$ & $44(34.6 \%)$ & 0.776 \\
& Female & $65(63.3 \%)$ & $33(33.7 \%)$ & \\
\multirow{2}{*}{ Residence Type } & Urban & $65(60.7 \%)$ & $42(39.3 \%)$ & 0.259 \\
& Rural & $77(68.8 \%)$ & $35(31.2 \%)$ & \\
\multirow{2}{*}{ School Background } & Public & $72(73.5 \%)$ & $26(26.5 \%)$ & $0.022^{\star}$ \\
& Private & $70(57.9 \%)$ & $51(42.1 \%)$ & \\
\hline
\end{tabular}

Similar results have been reported in a study on medical students from other universities [19] [20] [21] [22].

Students in the first year of medical school reported good health promotion lifestyles which declined in the students in other year groups. They have obtained the highest score on spiritual growth with a mean of 3.12 and lowest score on physical activity of 2.24 out of a scale of 4 . The fourth year students were weakest in interpersonal relation which we thought was a strange finding because students are engaged in community based learning and education activities as a part of curricular activities and have to work and interact with patients, health-centre staff and rural people in their communities many times during their training.

The study revealed that highest mean scores of HPLP among the six healthpromoting lifestyles were for spiritual growth and interpersonal relations whilst the lowest scores were for health responsibility and physical activity which is comparable with data from a high income region in Asia [19]. This finding is also consistent with other studies [21] [22] [23] [24]. Nepal is a culturally rich country where multiple religions co-exist, chief of them being Hinduism and Buddhism with small numbers of Muslims and Christians. Not only the older generation but the young also engage in prayers, God-worship and cultural rituals.

The score of health responsibility was poor $(<2.5$ mean score), which was contradicting with the results of studies conducted by Lee et al. [19] Montazeri et al. [22], and Adderley-Kelly et al. [25].

Additionally, the mean score of health promoting behaviors was higher among male respondents than that among the female, which was chiefly due to the greater score obtained by males on domain of physical activity. This was slightly different from the results of studies carried out by Díez et al. on Mexican students [26], Stock et al. on German students [27], and Von Bothmer et al. on Swedish students [28]. This hints at the cultural differences with respect to $\mathrm{Ne}$ pali women where female students are less involved in sports or other physical activities compared to men. It also points to a need for more women-friendly sports and physical activity infrastructure in educational institutions and cities in Nepal. 
It is known that demographic factors like age, residence type, education and school background have great role in determining health behaviors [21]. Urbanisation and access to transportation is greatly increasing throughout Nepal which means people have to walk less and do less physical work. The work of people is also shifting from the traditional manual labour, especially in agriculture, to other modes largely due to mechanization and also due to the increase in opportunity in services and trade. Our study shows that the physical activity scores are lower which is also a reflection of larger society in general.

This study also showed that physical activity and nutrition were the biggest predictors of healthy lifestyle in this student population. These domains are easily amenable to education, behavior change and other interventions like provision of commodities and infrastructure.

This study clearly shows that there is ample room for improvement in the health promoting lifestyle practices of medical students at PAHS and this could be representative of the students' population and youth over much of Nepal and also in the South Asian region. The low score in physical activity and health responsibility demands an intervention from both campus administration and public health authorities at a wider level. A healthy lifestyle must be a part of the curriculum and efforts must be directed to ensuring infrastructure and services towards creating a healthy lifestyle.

We were limited by the fact that this study collected data only from one university status educational organization with bachelor level medical students. These findings may not be generalizable to all students or all young adults. Therefore, a larger study of this type with a more representative sample of all university students, young adults or the general population should be carried out. Such a study should explore health promotion behaviors, study style, social environment or activities, and physical activities, nutrition and daily lives.

\section{Conclusion}

In general, the results of the present study revealed that the status of health promoting behaviors was of an acceptable level with ample room for improvement among the students at Patan Academy of Health Sciences, Nepal. In this study, physical activity and nutrition are the largest predictors of the lifestyle and they need to be modified for the subgroups where the scores are low. The necessity of the implementation of health education and promotion programs with an emphasis on different dimensions of health lifestyles behaviors is recommended. According to this study, a good number of medical students are not adopting health promoting lifestyle behaviors on daily basis and their life-style behaviors are low in the mirror of graduate competency of the Patan Academy of Health Sciences. Thus, the researchers would like to recommend that Academy and faculty can facilitate student learning about health and link this to living a healthy lifestyle. By "learning health" to "live health" future doctors can design appropriate programs that will provide a much-needed gamut of proven strategies to help others attain and maintain healthy lifestyles. 


\section{Acknowledgements}

We are grateful to all students who participated in this study for their kind support and cooperation.

\section{References}

[1] Edelman, C.L. and Mandle, C.L. (2006) Health Promotion throughout the Life Span. 6th Edition, Mosby, St. Louis.

[2] Ayaz, S., Tezcan, S. and Akınc1, F. (2005) Health Promotion Behaviour of Students at the Nursing College. Journal of Cumhuriyet University School of Nursing, 9 , 26-34.

[3] Han, K.S. (2005) Self Efficacy, Health Promoting Behaviors, and Symptoms of Stress among University Students. Journal of Korean Academy of Nursing, 35, 585-592. https://doi.org/10.4040/jkan.2005.35.3.585

[4] Kunwar, D., Risal, A. and Koirala, S. (2016) Study of Depression, Anxiety and Stress among the Medical Students in Two Medical Colleges of Nepal. Kathmandu University Medical Journal, 53, 22-26.

[5] Wei, C.N., Harada, K., Ueda, K., Fukumoto, K., Minamoto, K. and Ueda, A. (2012) Assessment of Health-Promoting Lifestyle Profile in Japanese University Students. Environmental Health and Preventive Medicine, 17, 222-227. https://doi.org/10.1007/s12199-011-0244-8

[6] Lee, R.L.T., Alice, J.T. and Loke, Y. (2012) Health-Promoting Behaviors and Psychosocial Well-Being of University Students in Hong Kong. Public Health Nursing, 22, 209-220.

[7] Chouhan, S. (2017) Analysing Health Promoting Life Styles of Medical Students in Bhopal, Madhya Pradesh, India by HPLP-II. International Journal of Community Medicine and Public Health, 4, 195-199. https://doi.org/10.18203/2394-6040.ijcmph20164737

[8] Mozaffarian, D., Hao, T., Rimm, E.B., Willett, W.C. and Hu, F.B. (2011) Changes in Diet and Lifestyle and Long-Term Weight Gain in Women and Men. The New England Journal of Medicine, 364, 2392-2404. https://doi.org/10.1056/NEJMoa1014296

[9] Majra, J.P. (2013) Do Our Medical Colleges Inculcate Health-Promoting Lifestyle among Medical Students: A Pilot Study from Two Medical Colleges from Southern India. International Journal of Preventive Medicine, 4, 425-429.

[10] Cerame, G., Meli, V., Vitale, F., Firenze, A., Viviano, E., Mazzucco, W. and Romano, N. (2008) A Study to Evaluate the Lifestyle of Medical Students in Palermo (Italy). Ig Sanita Pubbl, 64, 469-484.

[11] Carter, A.O., Elzubeir, M., Abdulrazzaq, Y.M., Revel, A.D. and Townsend, A. (2003) Health and Lifestyle Needs Assessment of Medical Students in the United Arab Emirates. Medical Teacher, 25, 492-496. https://doi.org/10.1080/01421590310001605633

[12] Norouzinia, R., Aghabarari, M., Kohan, M. and Karimi, M. (2013) Health Promotion Behaviors and Its Correlation with Anxiety and Some Students' Demographic Factors of Alborz University of Medical Sciences. Health Promotion Manager, 2, 39-49.

[13] Kickbusch, I. (2003) The Contribution of the World Health Organization to a New Public Health and Health Promotion. American Journal of Public Health, 93, 383-388. https://doi.org/10.2105/AJPH.93.3.383 
[14] Farhud, D.D. (2015) Impact of Lifestyle on Health. Iranian Journal of Public Health, 44, 1442-1444.

[15] Hong, J.F., Sermsri, S. and Keiwkarnka, B. (2007) Health-Promoting Lifestyles of Nursing Students in Mahidol University. Journal of Public Health and Development, 5, 27-40.

[16] Li, Y., Lindsey, B.J., Yin, X. and Chen, W. (2012) A Comparison of American and Chinese Student's Perceived Stress, Coping Styles and Health Promotion Practices. Journal of Students Affairs Research and Practice, 49, 211-227. https://doi.org/10.1515/jsarp-2012-6298

[17] Walker, S.N., Sechrist, K.R. and Pender, N.J. (1987) The Health-Promoting Lifestyle Profile: Development and Psychometric Characteristics. Nursing Research, 36, 76-81. https://doi.org/10.1097/00006199-198703000-00002

[18] Nepal Law Commission, Government of Nepal (2008) Patan Academy of Health Sciences Act, 2064. Nepal Law Commission, Kathmandu.

[19] Lee, R.L. and Loke, A.J. (2005) Health-Promoting Behaviors and Psychosocial Well-Being of University Students in Hong Kong. Public Health Nursing, 22, 209-220. https://doi.org/10.1111/j.0737-1209.2005.220304.x

[20] Kurt, A.S. (2015) The Relationship between Healthy Lifestyle Behaviours and Health Locus of Control among Nursing and Midwifery Students. American Journal of Nursing Research, 3, 36-40.

[21] Larouche, R. (1998) Determinants of College Students' Health-Promoting Lifestyles. Clinical Excellence for Nurse Practitioners, 2, 35-44.

[22] Montazeri, N., Kianipour, N., Nazari, B., Ziapour, A. and Bakhshi, S. (2017) Health Promoting Behaviors among University Students: A Case-Sectional Study of Kermanshah University of Medical Sciences. International Journal of Pediatrics, 5 , 5091-5099.

[23] Tol, A., Tavassoli, E., Shariferad, G.R. and Shojaeezadeh, D. (2013) Health-Promoting Lifestyle and Quality of Life among Undergraduate Students at School of Health, Isfahan University of Medical Sciences. Journal of Education and Health Promotion, 2, 29-32.

[24] Al-Kandari, F., Vidal, V.L. and Thomas, D. (2008) Health Promoting Lifestyle and Body Mass Index among College of Nursing Students in Kuwait: A Correlational Study. Nursing \& Health Sciences, 10, 43-50. https://doi.org/10.1111/j.1442-2018.2007.00370.x

[25] Adderley-Kelly, B. and Green, P.M. (2000) Health Behaviors of Undergraduate African American Nursing Students. ABNF Journal, 11, 7.

[26] Díez, S.M.U. and Pérez-Fortis, A. (2010) Socio-Demographic Predictors of Health Behaviors in Mexican College Students. Health Promotion International, 25, 85-93. https://doi.org/10.1093/heapro/dap047

[27] Stock, C., Wille, L. and Krämer, A. (2001) Gender-Specific Health Behaviors of German University Students Predict the Interest in Campus Health Promotion. Health Promotion International, 16, 145-154. https://doi.org/10.1093/heapro/16.2.145

[28] Von Bothmer, M. and Fridlund, B. (2005) Gender Differences in Health Habits and in Motivation for a Healthy Lifestyle among Swedish University Students. Nursing \& Health Sciences, 7, 107-118. https://doi.org/10.1111/j.1442-2018.2005.00227.x 
Submit or recommend next manuscript to SCIRP and we will provide best service for you:

Accepting pre-submission inquiries through Email, Facebook, LinkedIn, Twitter, etc. A wide selection of journals (inclusive of 9 subjects, more than 200 journals)

Providing 24-hour high-quality service

User-friendly online submission system

Fair and swift peer-review system

Efficient typesetting and proofreading procedure

Display of the result of downloads and visits, as well as the number of cited articles Maximum dissemination of your research work

Submit your manuscript at: http://papersubmission.scirp.org/

Or contact jbm@scirp.org 